\title{
Microsoft Teams for CEU and Training Delivery ${ }^{1}$
}

\section{Brett W. Bultemeier and Joe Gasper ${ }^{2}$}

With the inability to meet and conduct in-person pesticide training during the COVID-19 outbreak, many have had to utilize online teaching platforms. These online meetings have ranged from internal trainings among fellow county faculty, test preparation or other informative training for stakeholders, and secure continuing education training for pesticide applicators across the state. These various types of online gatherings have different purposes and priorities regarding information flow and interaction. As such, the online meeting platform needs to be flexible and adaptable to meet those needs. The purpose of this publication is to help Extension faculty become familiar with using Microsoft Teams for continuing education unit (CEU) training opportunities.

The Microsoft Teams ("Teams") collaboration platform is popular among UF/IFAS faculty, researchers, Extension agents, and staff for its ease of use and utility for internal and external communication, collaboration, and meetings. The Teams webinar feature called live events can be used for a more controlled experience for large meetings, events, or CEU delivery. This article will discuss the benefits and possible limitations of this service, specifically for offering online CEU material that meets Florida Department of Agriculture and Consumer Services (FDACS) guidelines for such trainings. For more information, training, and assistance regarding Teams, please join the UF/IFAS Microsoft Team called Jurassic County Extension (Note: requires UF login credentials to join).

\section{Microsoft Teams Meeting Types}

There are four types of meetings in Teams.

- Meet now (or ad hoc/instant) meeting-nonscheduled, 1:1 or 1:many

- Channel meeting_-scheduled, open to all team members

- Private (or general/stand-alone) meeting-scheduled, 1:1 or 1:many

- Live event (webinar)—scheduled, 1:many

Microsoft Teams and Microsoft Outlook are connected to your Exchange calendar, so a meeting scheduled in either application will show in the other. We recommend using the Teams calendar app as your primary meeting manager. With the assumption that you may be providing training to those outside the UF organization, this document will focus on private meetings and live events.

\section{Private Meetings}

A Teams private meeting is best when you have well-known attendees or registrants and you wish to have the option for interactive discussion or collaboration-ideal for internal team meetings with faculty, or even for groups outside UF. In the meeting itself, files can easily be shared, chats maintained, screens shared amongst participants, and the meeting recorded.

There are three roles in a Teams meeting: organizer (meeting creator), presenters, and attendees. Attendees

1. This document is PI290, one of a series of the Pesticide Information Office, UF/IFAS Extension. Original publication date April 2021. Visit the EDIS website at https://edis.ifas.ufl.edu for the currently supported version of this publication.

2. Brett W. Bultemeier, Extension assistant professor, UF/IFAS Pesticide Information Office; and Joe Gasper, systems administrator IV, UF/IFAS IT; UF/IFAS Extension, Gainesville, FL 32611.

The Institute of Food and Agricultural Sciences (IFAS) is an Equal Opportunity Institution authorized to provide research, educational information and other services

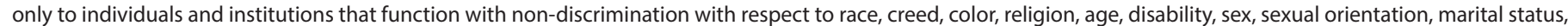

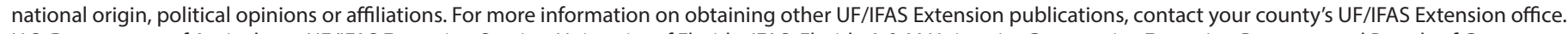
U.S. Department of Agriculture, UF/IFAS Extension Service, University of Florida, IFAS, Florida A \& M University Cooperative Extension Program, and Boards of County Commissioners Cooperating. Nick T. Place, dean for UF/IFAS Extension. 
can enable their web camera and microphone, use the raise hand function, and participate in the meeting chat. Individuals in the presenter role additionally can share content (screen, application, PowerPoint, Whiteboard), mute attendees, and promote/demote attendees to the presenter role. The organizer has the presenter role features, sets the meeting options, downloads the attendance report, can create and modify breakout rooms, and is an owner of a meeting recording.

Scheduling a Teams private meeting in the Teams calendar app is like how you have previously scheduled meetings in Outlook, only with the online component added. A private meeting does not require being a member of a team and can include external (non-UF) participants (no Teams license required). You can use the Scheduling Assistant to set required attendees, and attendees can be updated or the "join meeting" link shared once the meeting is set.

As the organizer, it is important to set the private meeting options for the optimal flow of your meetings. Once the private meeting has been scheduled, edit the meeting, and select meeting options.

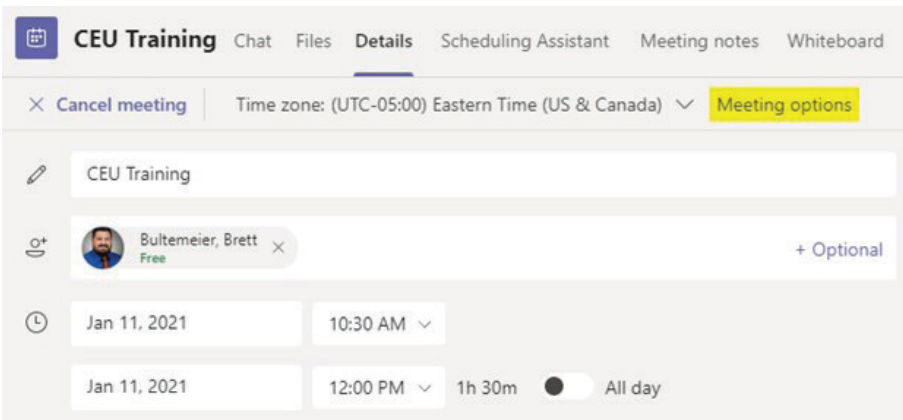

Under meeting options are settings for managing the lobby, specifying who has the presenter role, and disabling the ability for attendees to unmute their microphones.

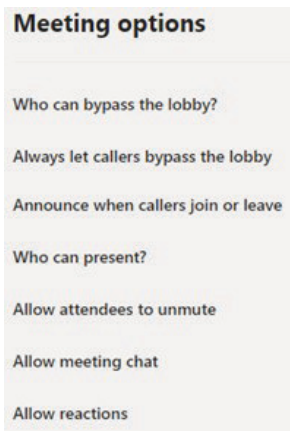

These options can be modified in the middle of an active meeting. For example, you may allow any attendees in the organization (UF) to bypass the lobby, requiring guests (non-UF) to enter the lobby, but 10 minutes into the meeting, switch the bypass lobby option to only me as a method to lock the participants. If you do not allow attendees to unmute ("hard mute") you can individually enable an attendee to unmute during the meeting and then hard mute them after they have spoken.

Note that you cannot unmute a participant's microphone; only the participant can unmute their microphone. If you have a large meeting, consider having an additional facilitator (someone with presenter role) who provides support for the lobby (looks up registrants before allowing them into the meeting), mutes attendees, and manages questions in the chat. A well-managed private meeting can provide a high level of interactivity and collaboration. Using the available meeting options can enable secure meeting and collaboration training sessions.

\section{Live Events}

A Teams live event provides a one-way, webinar-style meeting with the potential for TV studio production content. A live event is the best option when you are pushing content to attendees and you do not need interaction beyond typed questions and answers. Attendees in a live event do not have an active camera or microphone and can only use a moderated question and answer (Q\&A) function if enabled. We recommend enabling the Q\&A function when creating the live event, because you cannot enable it after creation (though you can disable Q\&A during the live event if desired). A live event adds some complexity to the meeting but reduces the necessity of managing attendees. You schedule a live event from the calendar app in Teams (Figure 1).

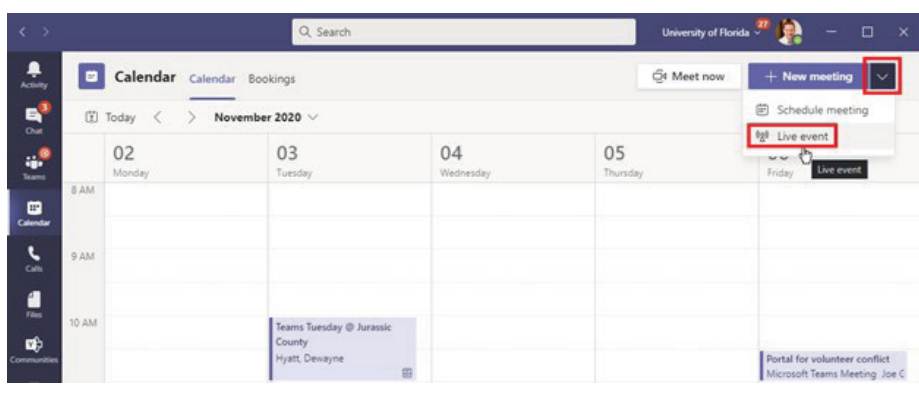

Figure 1. Meeting is the default selection, and live event can be found in the drop-down menu.

There are several roles in a live event. The person setting up the details of the meeting and ultimately controlling the live event is designated as the organizer and producer. You can have multiple producers (Figure 2). Producers have ultimate control over which presenter's content is sent live to the attendees and if that is simply their screen or both their screen and video. The producer decides when to start the live event, broadcasting it to the attendees, and when to end the live event. As a producer, think of the live event like a small TV newscast, where you control the script of the 
people on screen and the content shown. Note: once a live event has been ended, it cannot be restarted.

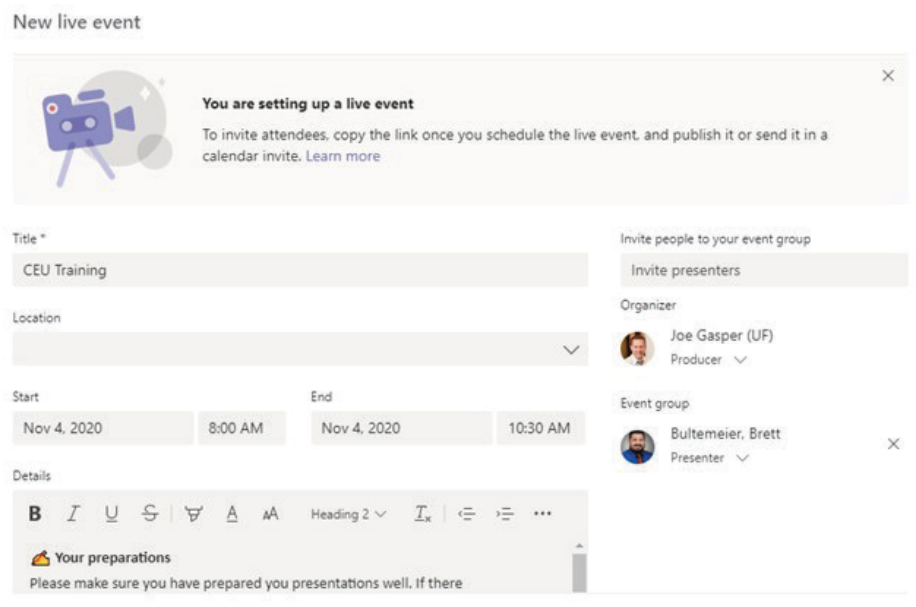

Figure 2. Scheduling of a live event starts with time, date, and presenter information.

As the event is created, or even after, a producer can add multiple presenters. These presenters can share their screen, video, and audio. Presenters and producers must use the Teams application, and presenters' experience will be like a Teams meeting. Once a live event has started, producers and presenters can use Teams chat to communicate, which is helpful to notify the next presenter to get ready. Note: producers and presenters should mute when not speaking because their audio is always live and sent to the audience. Guests (non-UF) can participate as presenters and producers. We recommend scheduling a test run for your live event with all producers and presenters to practice and ensure an understanding of the live event production and features.

Attendees to the live event join by a shared event link and can watch and participate with just a web browser or the Teams application. They can only interact with presenters and producers through the moderated Q\&A chat. When a live event is scheduled, an email with join information is sent to your required attendees (presenters/producers). This link can be shared with the attendees (if they do not have a presenter/producer role, they will enter as an attendee).

If a presenter is asking for responses during their presentation, be sure they understand the attendees are receiving the event feed 20 to 30 seconds after their live content. The delay is necessary to broadcast to the large number of possible attendees and enable automatic captioning and translation in up to 6 additional languages (must be set before start of the live event; see Figure 3).

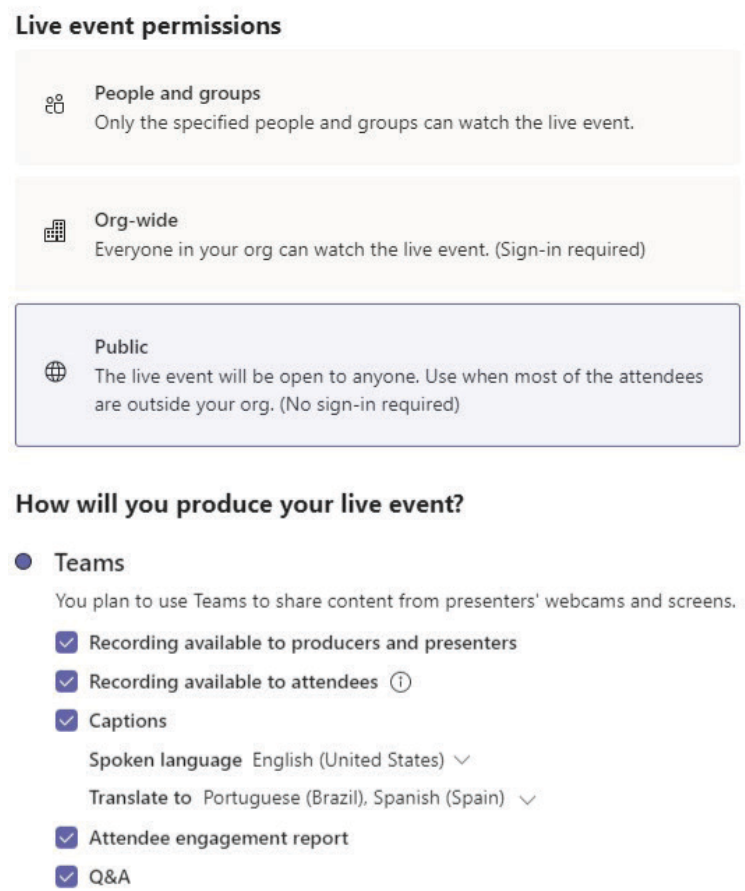

Figure 3. After initial meeting details, the numerous live event features can be enabled/disabled for the actual event.

A live event is scheduled on your Teams calendar just like a private meeting, but creation flow has additional screens to set controls and options. A live event is best designed for one-way communication for a person or group of people to reach a large audience.

The producer in live event can choose what to stream live and how the stage will look to the attendees. The producer can switch presenter content from preloaded material in the share bar (Figure 4). This allows close monitoring of the live event and seamless change to the next speaker, avoiding the awkward request for control and downtime in having it load. The producer can set the stage to show only a presenter's video, only their shared content, or an 80:20 view with content (80\%) and video (20\%) (Figure 5). As mentioned, when a presenter is planning to ask for attendee feedback via the Q\&A or has pushed out a poll link, remind them of the up to 30-second delay so they can plan for short filler content at these points. If interactive attendee engagement is not a requirement, a live event is ideal for delivering online content. We highly recommend reading the live events best practices document for additional information, tips, and troubleshooting. 


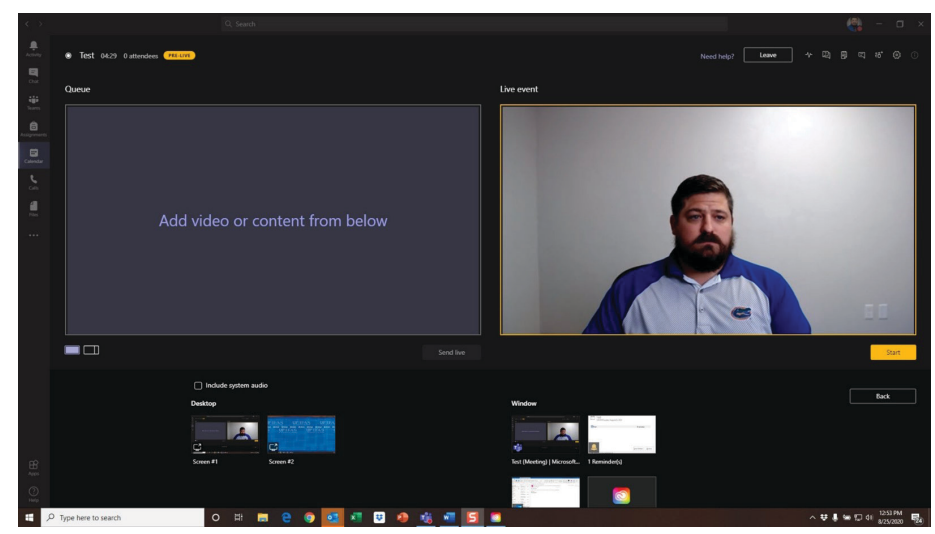

Figure 4. Producer view during a live event. This view is "Live" and participants see actual content $\sim 30$ secs after. This shows the alternate display mode for Teams (dark mode).

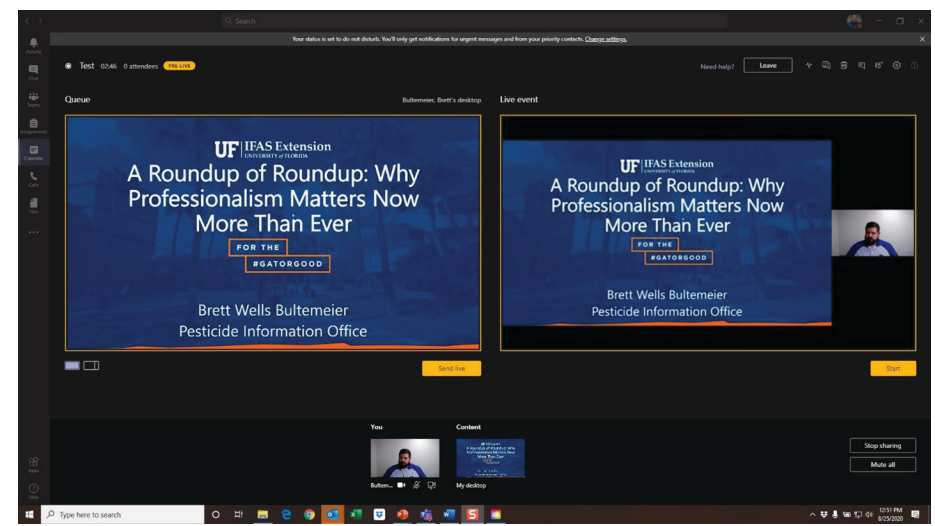

Figure 5. Producer view showing delay in actual view and showing just slides vs slide and presenter video. This shows the alternate display mode for Teams (dark mode).

Table 1. Comparison of Teams Meeting vs Live Event

\begin{tabular}{|l|l|l|}
\hline \multicolumn{1}{|c|}{ Feature } & \multicolumn{1}{|c|}{ Meeting } & \multicolumn{1}{c|}{ Live Event } \\
\hline Maximum participants & 300 & $20,000^{*}$ \\
\hline Who can present content & Presenters & $\begin{array}{l}\text { Presenters/ } \\
\text { Producers }\end{array}$ \\
\hline Chat & All attendees & Moderated Q\&A \\
\hline $\begin{array}{l}\text { Outside the organization } \\
\text { attendance }\end{array}$ & Yes & Yes \\
\hline Participant experience & Real time & 20-30 second delay \\
\hline $\begin{array}{l}\text { Maximum length } \\
\text { *After June 30, 2021: } \text { maximum participants = 10,000; maximum } \\
\text { length = 4 hours }\end{array}$ & 24 hours & 16 hours* \\
\hline
\end{tabular}

\section{CEU Specifics}

\section{Attendance Checks}

To meet the webinar requirements for FDACS-approved $\mathrm{CEU}$ events, the following must be in place:

1. Multiple engagement check-ins during the event.

2. Although there is no set standard, at least 1 attendance check during each 50-minute block is advisable.
3. Each individual attending must respond to the check-in in a timely manner. It is not sufficient to have a "group" response that represents more than one person.

For Teams meetings, the chat function can be used for engagements, and requiring the video feed be on could be helpful. For a live event, the Q\&A function could be utilized to ensure engagement. Alternately, a link to a predeveloped Microsoft Forms survey/poll/quiz that includes a series of questions can be shared in the Q\&A or chat. Participants click the link and complete the check-in. This feature can be used to verify attendance in either meeting or live event.

Because a Teams meeting is meant to be collaborative, ensuring engagement is easier in this platform, but controlling who is sharing (audio, video, chat) is more difficult. This can lead to conflict if an unruly participant wishes to disrupt the meeting (hard mute or remove and enable the lobby), or if an inexperienced user cannot mute their audio and background noise becomes a distraction (presenter role can mute attendees). By contrast, live event effectively manages distraction or disruption because it is designed for one-way communication from the presenters to the participants. However, checking attendance is more challenging and relies upon preplanned interactions in Microsoft Forms or requiring Q\&A participation. The organizer of the event must consider these pros and cons. If the group is small, knows one another, and is "well behaved," then a meeting with two-way communication could be ideal. For large statewide meetings with little direct knowledge of who is attending, a live event might be the better fit.

Steps and procedures that are not required but are helpful include the following:

- Engagements should be staggered throughout the event. Only checking at the beginning or end of a presentation is not recommended.

- Don't simply check attendance; encourage the audience to participate throughout. This will not only check attendance but make for a more enjoyable experience for participants.

- Polls and chat functions are both adequate means to check attendance.

To become a CEU provider and for more information, visit FDACS' CEU Page.

As CEU programs have moved back to some in-person meetings and new types of meetings have become relevant, a hybrid live and digital presence type of meeting is likely to become "the new norm." In this scenario, presenters 
from across the state (or across the county, or international) would all present to people gathered in live locations (such as UF/IFAS Extension offices). This scenario blends both worlds and might lend itself better to a live event. This will ensure a well-produced and well-delivered event, because the interaction is one-way to the audience, but they are able to interact back with the "host agent" at their physical location. It would also allow those still unable to join in person the ability to engage with the content and earn CEUs.

\section{CEU Forms}

Handing out CEU forms at in-person trainings is commonplace but is more challenging in a digital environment. Consider the following options when ensuring CEUs are counted for those attendees who adequately engaged in the material and would qualify for CEUs.

- Create a Microsoft Form or other "registration" type of document that asks for name and license number. This information will be needed for uploading CEUs to FDACS.

- Attendees that met requirements could then be copied and uploaded into the FDACS spreadsheet and placed into the CEU upload tool that CEU providers have access to (CEU Provider Login).

- CEU forms must be distributed if requested, but this can be minimized by communicating that as the provider, you are uploading their material.

- Emailed CEU forms should have, at a minimum, their name and license number already filled in. If this is done as a PDF, make sure it can't be further edited. 